\title{
Numerical And Experimental Thermal Inertia Characterization Of An Integrated Insulation Clay Hollow Block For Buildings Thermal Comfort Applications
}

\author{
Jean-Baptiste Bouvenot ${ }^{1,2^{*}}$, Vincent Jimenez ${ }^{1}$, Lucas Desport ${ }^{1}$, Monica Siroux ${ }^{1,2}$ \\ ${ }^{1}$ National Institute of Applied Sciences of Strasbourg, Strasbourg, France \\ ${ }^{2}$ ICube Laboratory, Strasbourg, France
}

\begin{abstract}
Integrated insulation clay hollow blocks present a complex geometry with 2 different materials: clay and mineral wool along high thickness (from 30 to $42,5 \mathrm{~cm}$ here) with integrated thermal bridges. The equivalent thermal conductivity $\lambda_{e q}$ is often well known for energetic calculations but the equivalent density $\rho_{e q}$ and heat capacity $c_{p e q}$ are not assessed. The aim here is to propose a method to obtain the equivalent parameters linked to thermal inertia to be used in an energy building simulation tool, which always supposes uniform materials layers and 1D thermal transfers.

This method is composed of a numerical phase and an experimental phase. At first, a 1D finite difference model has been created in order to simulate the thermal behavior of this kind of block. Then, an experimental test bench has been created based on two $1 \mathrm{~m}^{3}$ climatic rooms and a $1 \mathrm{~m}^{2}$ wall sample holder in order to calibrate the 1D model thanks to experimental data. An optimization procedure lets to identify the equivalent thermal properties of a uniform block which presents the same dynamic thermal behavior. Finally, a validation is carried out by comparing TRNSYS simulations and in situ experimental data in a dwelling building.

The novelty of this work is to propose an original and complete approach on inertia properties characterization of a complex geometry of modern blocks by a complete procedure from a 1D mode, experimental tests, in situ tests and TRNSYS simulations. The main result show a low thermal capacity for all of these blocks in comparison with others construction materials with $\rho_{e q} c_{p e q}=269500$ $\mathrm{J} . \mathrm{m}^{-3} \cdot \mathrm{K}^{-1}$ for CLIMAmur36 blocks.
\end{abstract}

\section{Introduction}

Integrated insulation clay hollow blocks is an interesting constructive system in the context of Near Zero Energy Buildings (NZEB) and energy efficiency. Besides, summer comfort purpose becomes a major concern in the European context, especially with regard to future climate changes. The inertial behavior of this kind of blocks has to be well known to assess its natural performance to guarantee this summer comfort in a passive way. That's why it's important to know the classical thermal properties (thermal conductivity, density and heat capacity) of these complex blocks in order to carry out energy building simulations.
The majority of construction materials are homogeneous and their physics properties (thermal conductivity $\lambda$, density $\rho$, heat capacity $c_{p}$ ) are often well known and compiled in reliable data banks (CSTB, 2017) or in buildings energy simulation tools like TRNSYS, Energy Plus or Pleiades COMFIE for example. However, this approach is not well adapted for many construction materials because of their geometry complexity like hollow bricks for example (Habib, 2017). For complex constructive systems like hollow clay blocks or integrated insulation hollow clay blocks, data giving the steady state behaviour $\left(\lambda\right.$ in $\mathrm{W} \cdot \mathrm{m}^{-1} \cdot \mathrm{K}^{-1}$ or $\mathrm{R}$ in $\left.\mathrm{m}^{2} . \mathrm{K} \cdot \mathrm{W}^{-1}\right)$ are well known (manufacturer data) and well compiled (CSTB, 2017). However, there is a big lack of data about steady and mainly unsteady behaviour. Some authors work on clay hollow blocks but the majority investigates only the steady state behaviour $\left(\lambda_{\text {eq }}\right)$ like Alghamdi et al. (2017) who propose a $3 \mathrm{D}$ finite element numerical model or Koci et al. (2015) who propose a numerical model to determine steady state behaviour of hollow clay blocks integrating different kinds of insulation materials. Some authors work on unsteady thermal behaviour like Habib et al. (2017) who only study the time-lag (phase shift) according to the block response time (BRT) and by considering simplified and non validated equivalent thermal properties $\left(\rho_{e q}\right.$ and $\left.c_{p e q}\right)$. More generally, several works dealt with the thermal comfort of clay blocks (CTTB, 1997; Brambilla 2017) but the majority of them studies heavy clay blocks with sometimes poorly adapted experimental procedures (indoor temperature imposed to a constant value although the aim is to study amplitude damping performances) (CTTB, 1997). These studies never propose identification procedures of equivalent unsteady thermal properties.

For more modern blocks integrating mineral insulation in bigger cavities (see Fig. 1), the question of inertia will be more crucial because if the insulation is integrated and therefore distributed, the inertia is also distributed.

The problematic, is, even if the block contains mass in clay, what is the effective thermal inertia brought by this kind of blocks for the ambient temperature natural control? 


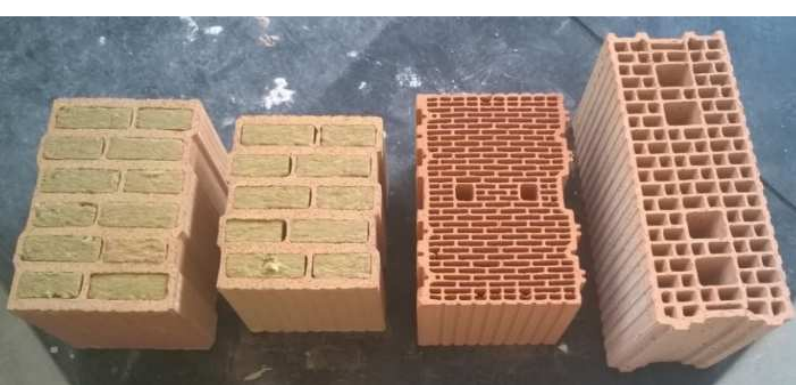

Figure 1: Integrated insulation hollow clay blocks (left) and classical hollow clay blocks (right) samples (Wienerberger blocks references from left to right: CLIMAmur 36, CLIMAmur 30, R37, GF R20).

\section{Method}

The method is composed of 2 phases. Each phase is composed of an experimental part and a numerical part.

At first, an experimental study is led to investigate the steady and unsteady thermal behaviour of a wall sample $\left(1 \mathrm{~m}^{2}\right)$ in controlled conditions thanks to a guarded hot box composed of two $1 \mathrm{~m}^{3}$ climatic rooms and a $1 \mathrm{~m}^{2}$ wall sample holder. Each room simulates dynamically indoor and outdoor climates (temperature and humidity). Two procedures will be distinguished to determine on one hand the equivalent thermal conductivity by using steady state tests and on the other hand unsteady state tests to identify the inertia terms $\left(\rho_{e q}\right.$ and $\left.c p_{e q}\right)$. In parallel, a 1D finite difference model is programmed to simulate the dynamic thermal behaviour of these blocks. An optimization procedure based on the classical least squares method will compare 1D model outputs with experimental outputs to find the equivalent thermal properties: $\left(\rho_{e q}\right.$ and $\left.c p_{e q}\right) . \lambda_{e q}$, being determined by steady state tests.

Then, for the second phase, we will inject the equivalent thermal properties in a TRNSYS simulation of a real dwelling building. In parallel, we carry out an in situ test in this real building by using a meteorological station (the real meteorological data will be used in the TRNSYS simulation), and non-intrusive metrology (temperature probes, heat flux-meters and shading position sensors). Finally, we validate the equivalent properties by comparing TRNSYS outputs with in situ tests measurements. Figure 2 summarizes our scientific approach:

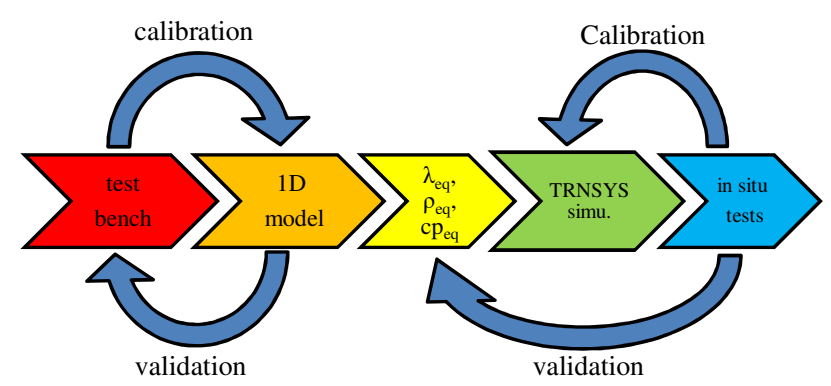

Figure 2: Method principle scheme.

\section{Experimental test bench}

The first step of the method consists by carrying out experimental tests on a $1 \mathrm{~m}^{2}$ wall sample built between two $1 \mathrm{~m}^{3}$ climatic rooms whose ambiances are dynamically controlled. The first climatic room emulates indoor conditions, the second emulates outdoor conditions (see. Fig. 3).

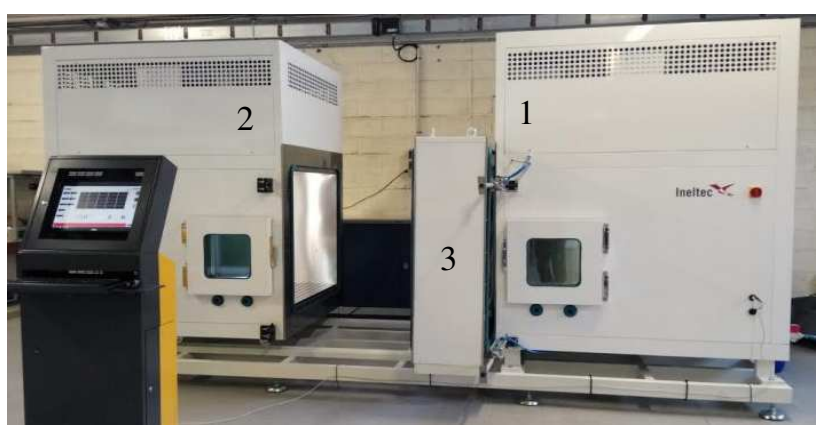

Figure 3: Test bench (1: indoor climatic room, 2: outdoor climatic room, 3: wall sample carrier).

Outdoor conditions where fixed over $24 \mathrm{~h}$ by considering 2 sinusoidal scenarios based on 1981-2010 means, max and min values from 3 French cities which characterizes a "mean" French climate (see Fig 3).

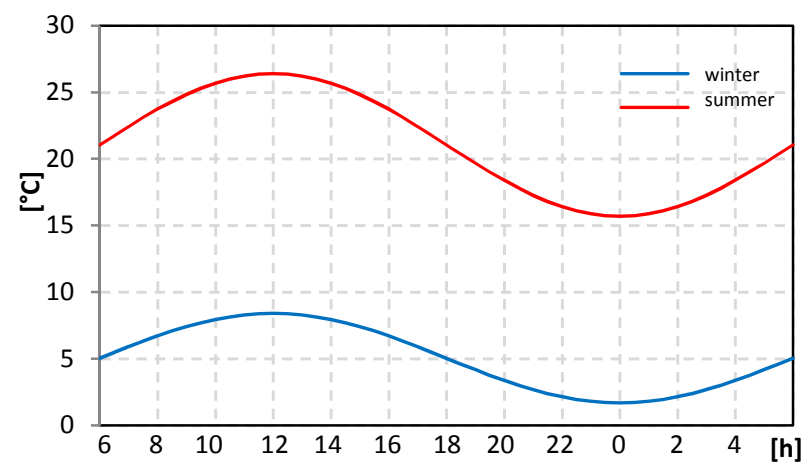

Figure 3: Outdoor temperature variation imposed in the "outdoor" climatic room.

For the indoor temperatures, we have to fix the temperature variation because the thermal inertia of the climatic room is not representative of a standard building behaviour. Besides, we cannot simulate the building behaviour built with these blocks because it's what we are investigating. We have to simulate the "natural derivation" of the indoor temperature by imposing the daily variation: in winter, we assume a constant temperature with night set point decrease and we assume a sinusoidal variation in summer by considering a fixed phase shift and damping (see Fig. 4).

The relative humidity set points are always fixed to $50 \%$ indoor and to $50 \%$ outdoor. 


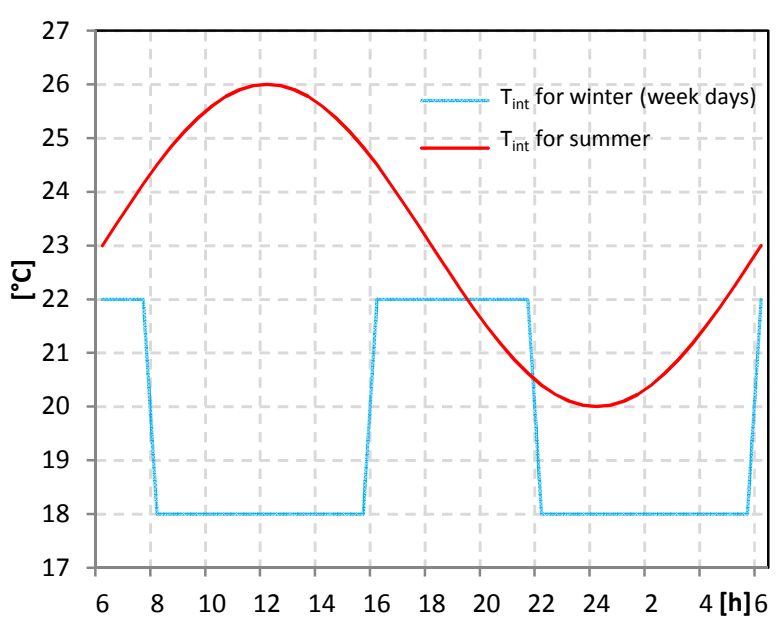

Figure 4: Indoor temperature variation imposed in the "indoor" climatic room.

The idea is to test the wall sample in realistic conditions we can easily found in standard cases. The accuracy of these values is not important here, we just want to avoid extreme conditions or unrealistic conditions.

Then, a wall samples have been built by using a brick reference from Wienerberger company presented in Fig. 1 (CLIMAmur 36). Each construction respects the rules of the art that would be used on a real building site (mortar, glue, joint, plaster). The wall integrates $8 \mathrm{~K}$ thermocouples (K-TC) probes through 2 blocks located in the middle of the sample to avoid border effects. Then, we add on inner face a heat flux-meter and K-thermocouple surface sensors (see Fig. 5 and 6).

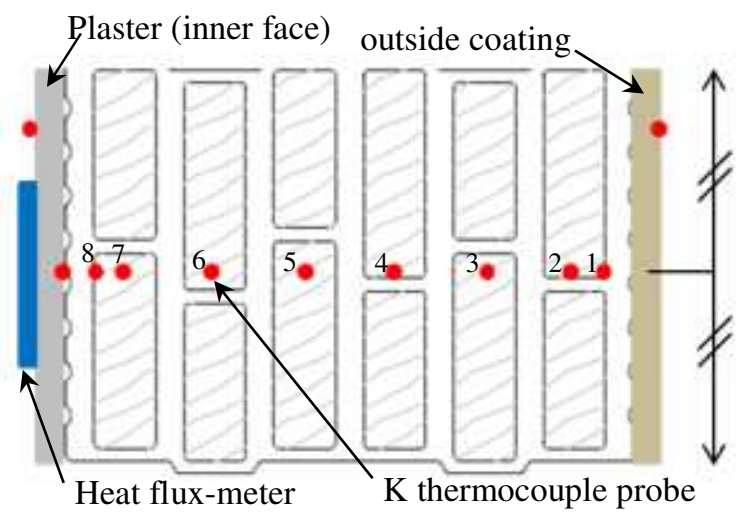

Figure 5: Metrology locations.

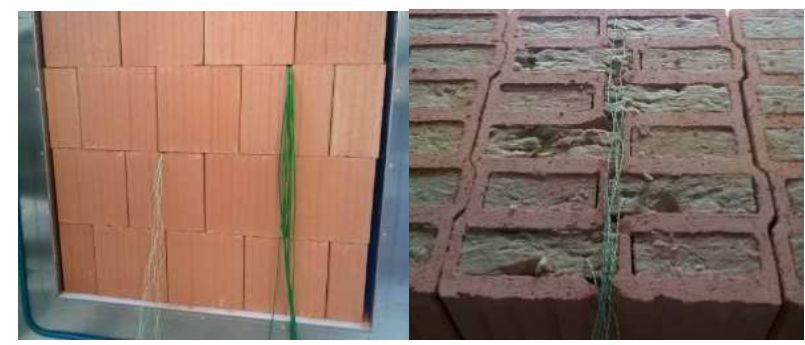

Figure 6: Wall sample and thermocouples location.

We summarize the metrology technical data in table 1:
Table 1: Metrology features.

\begin{tabular}{|c|c|c|c|}
\hline \multicolumn{4}{|c|}{ Metrology } \\
\hline Quantity & Technology & Range & Uncertainty \\
\hline Temperature & K thermocouple & $-75-150{ }^{\circ} \mathrm{C}$ & $\pm 0,8 \mathrm{~K}$ \\
\hline $\begin{array}{c}\text { Global flux } \\
\text { density }\end{array}$ & $\begin{array}{c}\text { T thermocouple } \\
\text { (Captec) }\end{array}$ & $-\infty-+\infty$ & $\pm 3 \%$ \\
\hline \multicolumn{4}{|c|}{ Acquisition devices } \\
\hline \multicolumn{3}{|c|}{ Device } & Reference \\
\hline Nanovoltmeter (for flux-meters) & Keithley 2182 A \\
\hline \multicolumn{2}{|c|}{ Acquisition module } & NI Compact DAQ \\
\hline
\end{tabular}

\section{$1 D$ finite difference models}

In parallel, a dynamic 1D finite difference model has been carried out to emulate the thermal behaviour of this kind of integrated insulation clay hollow blocks. A $2 \mathrm{~mm}$ homogeneous spatial step $\Delta \mathrm{x}$ has been used. We give for example in equation 1 , the discretized formula used in a central node by considering a time step of $\Delta \mathrm{t} 1 \mathrm{~s}$ and an explicit numerical scheme:

$$
\begin{gathered}
T(t)=\left(1-2 F_{o}^{*}\right) T(t-\Delta \mathrm{t})+F_{o}^{*}(T(x-\Delta \mathrm{x})+T(x+\Delta \mathrm{x})) \\
\text { with } F_{o}^{*}=\frac{\lambda_{e q}}{\rho_{e q} c_{p e q}} \frac{\Delta t}{\Delta x^{2}}
\end{gathered}
$$

\section{Steady state tests}

The first procedure aims to confirm experimentally the value for the equivalent thermal conductivity $\lambda_{e q}$ of these blocks thanks to a long steady state test and thanks to metrological means (heat flux meters mainly). According to the geometry of the blocks (thickness $e$ ) and the mean flux density output $\bar{\varphi}$, we can compute the equivalent thermal conductivity and compare it to manufacturer data (see Eq. 2):

$$
\begin{gathered}
\lambda_{e q}=\frac{e}{\frac{\Delta T}{\bar{\varphi}}-\frac{1}{h_{i}}-\frac{1}{h_{e}}} \\
\text { with } h_{i}=h_{e}=22,5 \mathrm{~W} \cdot \mathrm{m}^{-2} \cdot \mathrm{K}^{-1}
\end{gathered}
$$

It is to note that the superficial exchange coefficients $h_{i}$ and $h_{e}$ were previously determined by specific tests. They are intrinsic to the room and not modifiable (linked to the geometry and the internal ventilation system that aims to mix the air to obtain a uniform temperature in the climatic room). This operation generates high convection coefficients that are not currently realistic for indoor applications but are suitable for outdoor conditions.

\section{Unsteady state tests}

Then, we apply the dynamic boundary conditions to assess by identification the inertial terms: $\rho_{e q}$ and $c p_{e q}$ values. In fact, we will only consider 1 term: the volume heat capacity: $\rho . c p_{e q}$ in $\mathrm{J} \cdot \mathrm{m}^{-3} \cdot \mathrm{K}^{-1}$ because there are physically always linked in the fundamental physic formula for the computation (in the accumulation term).

\section{TRNSYS simulations}

TRNSYS is a robust and powerful building energy simulation software which is well adapted here. Indeed, this tool can compute many outputs in addition to classical outputs (air temperature and heating and cooling loads) like heat flux through the walls and wall temperatures that can be compared with the heat flux-meters and $\mathrm{K}$ thermocouples outputs. As soon as the thermal properties have been identified, a second procedure has been carried 
out. The aim is to assess the thermal inertia brought by these blocks. This assessment is made in 2 steps: the first is to simulate a real building with TRNSYS to observe the inner surfaces, air temperatures and the thermal comfort brought by this building system. Finally, an in situ test has been led to calibrate the TRNSYS model and to verify in real conditions the inertial behavior of these blocks. A real project has been chosen: a dwelling building which is built with CLIMAmur 36 blocks in Alsace region (NorthEast of France) (see Fig. 7).
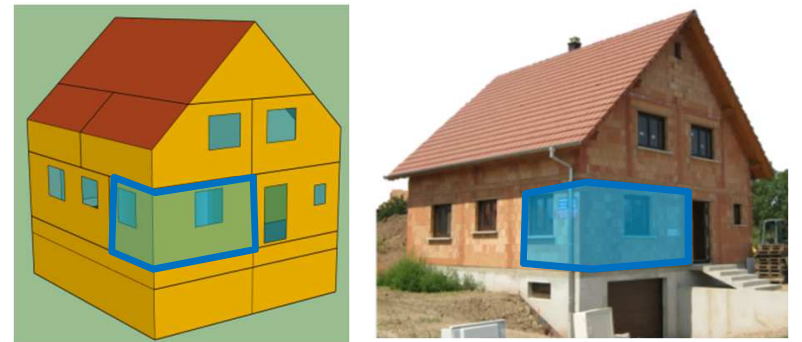

Figure 7: Studied dwelling perspective (TRNSYS 3D on In situ tests left with instrumented room in blue).

For the in situ tests, we instrumented a specific room which presents a double exposition: East and South (see Fig. 7 highlighted in blue). Obviously, it would have been more interesting to test several rooms and even several buildings but we limited the number of instrumented rooms because of the limitation of available sensors (heat flux meter mainly and only 1 meteo station) and to limit the inconvenience for inhabitants (heat flux meters and TC probes stuck on the wall and suspended TC probes). Besides, it is also complicated to find compliant people and suitable buildings. The metrological means are presented in Table 2.

Table 2: In situ test metrology features.

\begin{tabular}{|c|c|c|c|}
\hline Device & Type & Sensibility & Accuracy \\
\hline $\begin{array}{c}\text { Temperature } \\
\text { probes }\end{array}$ & T thermocouples & $\begin{array}{c} \pm 0,1 \% \\
+0,5^{\circ} \mathrm{C}\end{array}$ \\
\hline Data logger & $\begin{array}{c}\text { GRAPHTEC midi } \\
\text { LOGGER GL220 }\end{array}$ & $\begin{array}{c}1 \mu \mathrm{V} \text { à } \\
0,01 \mathrm{~V}\end{array}$ & $\pm 0,1 \%$ \\
\hline $\begin{array}{c}\text { Heat Flux- } \\
\text { meter }\end{array}$ & Thermocouples & $\begin{array}{c}170 \\
\mu \mathrm{V} /\left(\mathrm{W} / \mathrm{m}^{2}\right)\end{array}$ & $\pm 3 \%$ \\
\hline Meteo station & Davis Pro Vantage2 & \multicolumn{2}{|c|}{} \\
\hline
\end{tabular}

\section{Results and Discussion}

\section{Steady state tests}

We carried out a test over 18 hours where we imposed a constant temperature difference between indoor and outdoor rooms $(30 \mathrm{~K})$. Then, according to the mean flux density over the steady state period $\bar{\varphi}$, we computed the equivalent thermal conductivity and compared it to manufacturer data (see Eq. 2, Fig. 8 and Table 3):

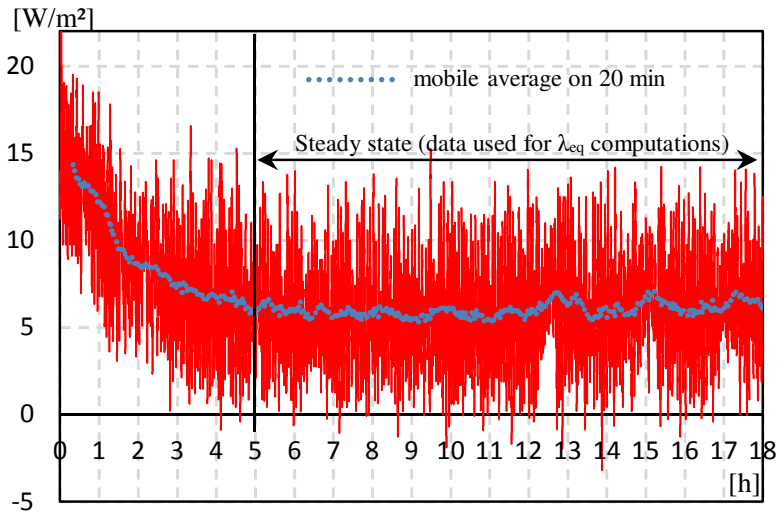

Figure 8: Steady state test results in terms of heat flux density for $\lambda_{\text {eq }}$ identification.

Table 3: Equivalent thermal conductivity of CLIMAmur 36 bricks.

\begin{tabular}{|c|c|c|c|}
\hline \multirow{2}{*}{$\begin{array}{c}\text { Thermal } \\
\text { properties }\end{array}$} & \multicolumn{3}{|c|}{ CLIMAmur 36 } \\
\cline { 2 - 4 } & Test & Manufacturer data & Deviation \\
\hline$\lambda_{\text {eq }}\left[\mathrm{W} \cdot \mathrm{m}^{-1} \cdot \mathrm{K}^{-1}\right]$ & 0,0750 & 0,0785 & $-4,5 \%$ \\
\hline
\end{tabular}

The equivalent thermal conductivity is very close to the manufacturer data and will be considered as validated.

Then, we note a high variability in the heat flux measurements (sampling rate of $10 \mathrm{~s}$ ). We can explain it mainly by the high turbulence in the room that generates this phenomenon. By smoothing the data over 20 minutes, we obtain a stable trend that leads to the equivalent conductivity computation.

\section{Unsteady state tests vs 1D model}

We started by using the tabulated data given in the French standard (CSTB ,2017) for each elementary materials: mineral wool and clay to compare the numerical model with the laboratory dynamic tests. At first, we checked, that conductive heat transfers in the initial 2D geometry can be assimilated to 1D heat transfers. An unsteady state 2D finite volume model has been programmed and show that the isothermal lines are comparable to parallel lines and perpendicular lines to the borders which justify the hypothesis of a 1D heat diffusion (see Fig. 9).

The influence of the internal thermal bridges is therefore neglectable from the point of view of the heat diffusion direction. The simplification in a $1 \mathrm{D}$ model is therefore relevant.

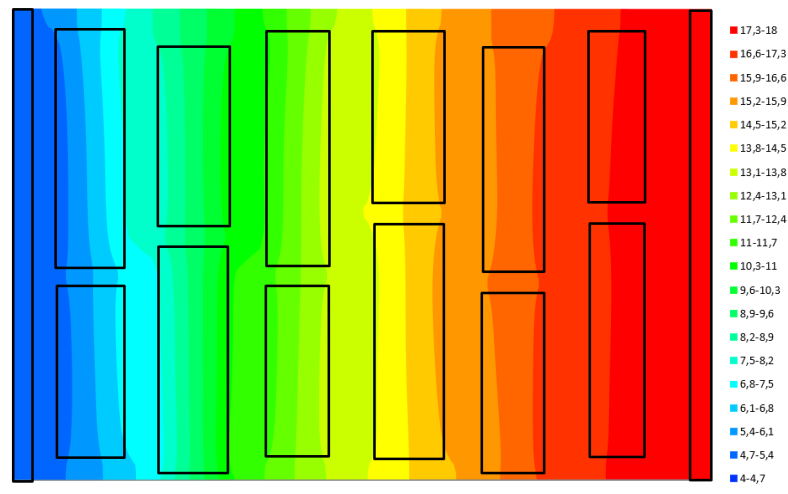

Figure 9: Isothermal lines from the 2D finite volume model. 
Secondly, we computed a volume weighted average of the volume heat capacity like used also Habib et al. (2017):

$$
\rho c_{\text {peq }}=\frac{V_{\text {wool }}\left(\rho c_{p}\right)_{\text {wool }}+V_{\text {clay }}\left(\rho c_{p}\right)_{\text {clay }}}{V_{\text {tot }}}=506400 \mathrm{~J} / \mathrm{m}^{3} / \mathrm{K}
$$

Then, we used this weighted average in the 1D model and it generated inconsistent curves in terms of dynamic (phase shift and amplitude) in comparison with experimental data. We quickly noticed that the "real" equivalent volume heat capacity $\left(\rho . c_{p}\right)_{e q}$ is lower than expected. Then, a parametric study has been launched by using a least squares method on both whole data on the 8 thermocouples data, amplitude values and phase shift values in order to identify the equivalent volume heat capacity value $\left(\rho . c_{p}\right)_{e q}$ of this block which reaches $269500 \mathrm{~J} \cdot \mathrm{m}^{-3} \cdot \mathrm{K}^{-1}$. It was important here to take into account the dynamic features in addition to the temperatures to be sure that experimental sinusoidal curves are synchronous with the 1D model and so in terms of amplitude and phase shift. That's why the least squares method was applied on these 3 parameters (temperatures, amplitude and phase shift for each thermocouple). Figures 10 and 11 compare the outputs from the optimized 1D model with experimental data (temperatures and fluxes). The correlation is very satisfying for the winter configurations. Bigger deviations appear for the summer case mainly for the thermocouples 7 and 2, but the dynamic is relevant by considering a deviation (about 1 $\mathrm{K}$ ) in the same range than the order of magnitude of the sensor uncertainty $( \pm 0,8 \mathrm{~K})$.

$\left[{ }^{\circ} \mathrm{C}\right]$

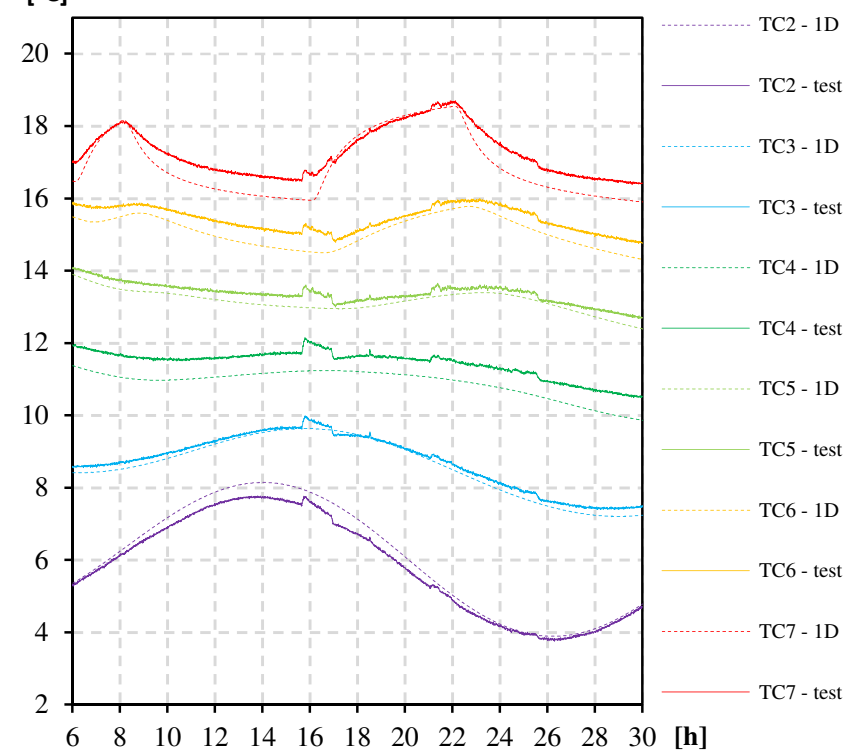

Figure 10: Wall inside temperatures comparison between $1 D$ model and laboratory test in winter conditions.

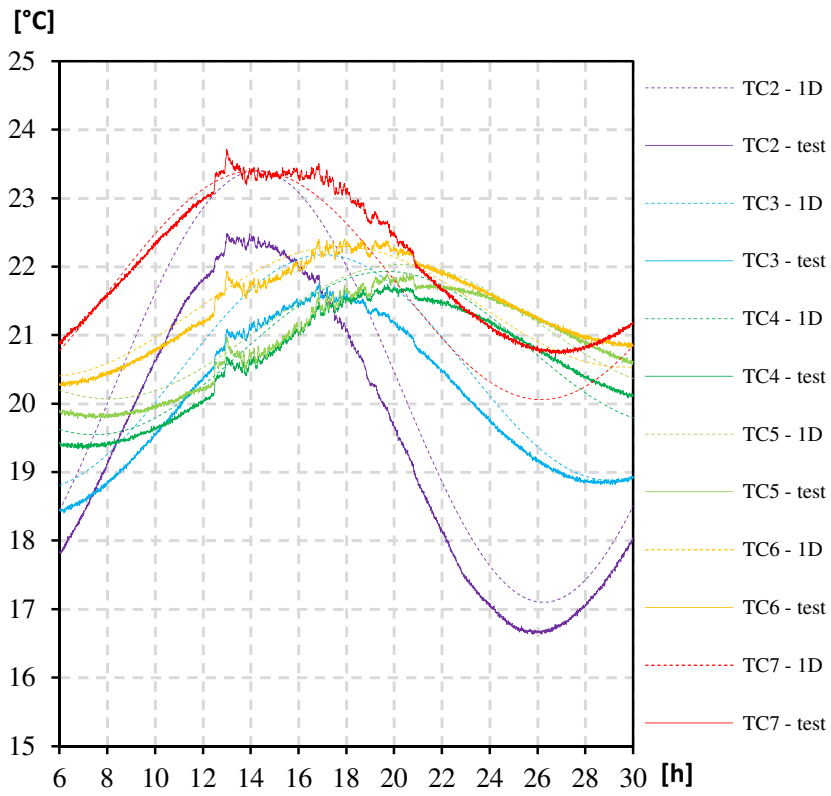

Figure 11: Wall inside temperatures comparison between 1D model and laboratory test in summer conditions.

With regard to inertia, it is important to check that the amount of energy incoming and outcoming of the inner wall (heat storage/heat destocking) is also consistent. Figures 12 and 13 show these algebraic flux densities for respectively winter and summer cases by comparing 1D model data and experimental tests.

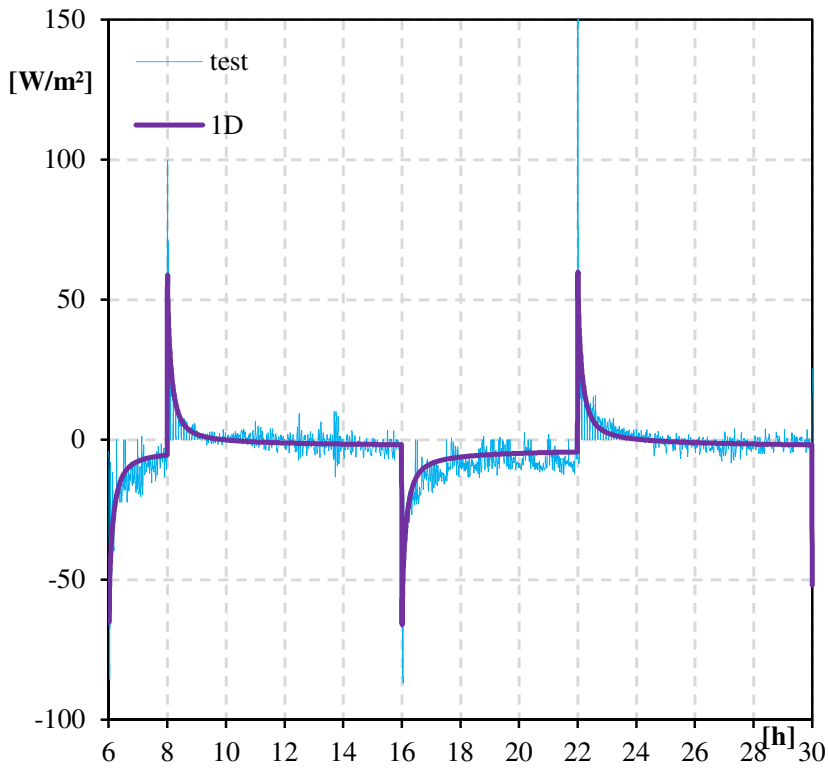

Figure 12: Indoor heat flux density evolution in winter. 


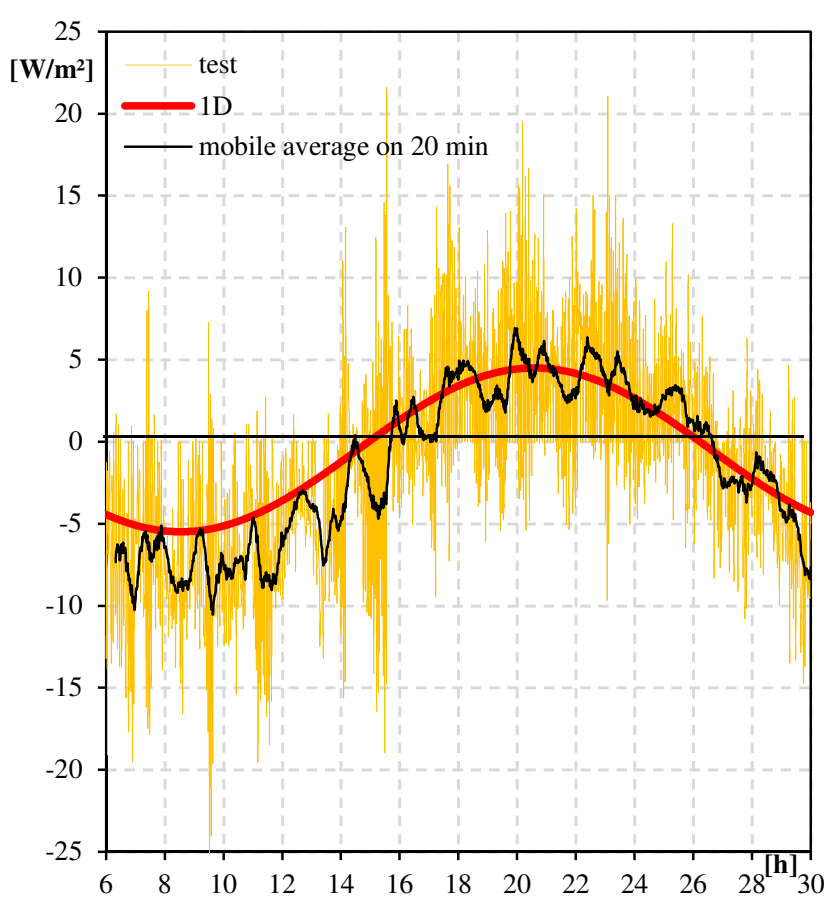

Figure 13: Indoor heat flux density evolution in summer.

We see a good correlation between the simplified numerical model and the experimental outputs mainly for the winter conditions. In summer, we well observe the storage phase during the day (positive values) and the destocking phase during the night (negative values).

\section{Equivalent thermal properties}

Finally, for building energy simulations, we will use the following data in Table 4 for each thermal property. We note that we use the data of the apparent density supplied by the manufacturer (global block mass divided by the block external volume) that leads to only adjust $c_{p e q}$ :

Table 4: Equivalent thermal properties.

\begin{tabular}{|c|c|}
\hline Properties & CLIMAmur 36 \\
\hline$\rho_{e q}$ & $630 \mathrm{~kg} \cdot \mathrm{m}^{-3}$ \\
\hline$c_{p e q}$ & $430 \mathrm{~J} \cdot \mathrm{kg}^{-1} \cdot \mathrm{K}^{-1}$ \\
\hline$\lambda_{e q}$ & $0,08 \mathrm{~W} \cdot \mathrm{m}^{-1} \cdot \mathrm{K}^{-1}$ \\
\hline
\end{tabular}

The $c_{p e q}$ value seems to be low in comparison with classical data (CSTB, 2017). A first explanation can be that tabulated values are often default values and probably wrong values (about $1000 \mathrm{~J} / \mathrm{kg} / \mathrm{K}$ for many construction materials) (CSTB, 2017). A second explanation is linked to the daily heat penetration depth $\delta$ (see Eq. 4): concept which assesses the "useful" thickness of a material when subjected to periodic solicitations (depth from which the amplitude of the signal is damped by the Euler factor e =
$2,72(-63 \%))$. A low equivalent heat capacity could mean that only a part of the brick is "activated" for the tested conditions (period of $24 \mathrm{~h}$ and amplitude of some K).

$$
\delta=\sqrt{\frac{\lambda_{e q} \tau}{\pi \rho_{e q}{ }_{p e q}}} \text { with } \tau=24.3600 \mathrm{~s}
$$

Here, if we compute this penetration depth, we obtain about $9 \mathrm{~cm}$ for the CLIMAmur 36 block that means that the internal heat wave only propagates on the first $9 \mathrm{~cm}$. This phenomenon could explain this quite low $c_{p e q}$ value. Finally, we found the same trend (low equivalent heat capacities) for 2 others references of clay hollow blocks (without mineral wool integrated (see Fig. 1)) with 437 $\mathrm{J} / \mathrm{kg} / \mathrm{K}$ for the R37 blocks and $475 \mathrm{~J} / \mathrm{kg} / \mathrm{K}$ for the GF R20 blocks from Wienerberger manufacturer. Besides, for an homogeneous massive material (aerated concrete) we applied the same experimental protocol and we found a consistent value of $800 \mathrm{~J} / \mathrm{kg} / \mathrm{K}$ in comparison with a tabulated value of about $1000 \mathrm{~J} / \mathrm{kg} / \mathrm{K}$.

\section{TRNSYS simulations vs in situ tests}

The studied dwelling building (see Fig. 7) has been modeled in the TRNSYS 17 environment. Internal loads and shading scenario have been made according to a survey of occupant habits and sensors analysis (shading contact sensors). In particular, quick morning natural and manual ventilation by windows openings have been taken into account to be more realistic (see highlight on Fig.15).

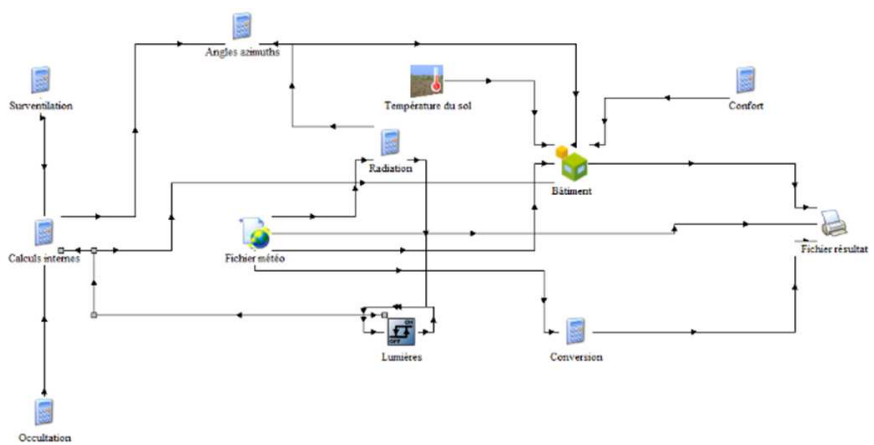

Figure 14: TRNSYS Studio model.

Figures 15 to 16 compare TRNSYS outputs with in situ measurements during the hottest week. After a calibration procedure, mainly on the shading rate during periods of direct sunlight and on the solar absorptivity coefficient of outer faces, we found a satisfying correlation. Finally, 89 $\%$ of the TRNSYS air temperature outputs are contained inside the uncertainty range of the sensors in addition to a satisfying shape of the curves in terms of dynamic. 


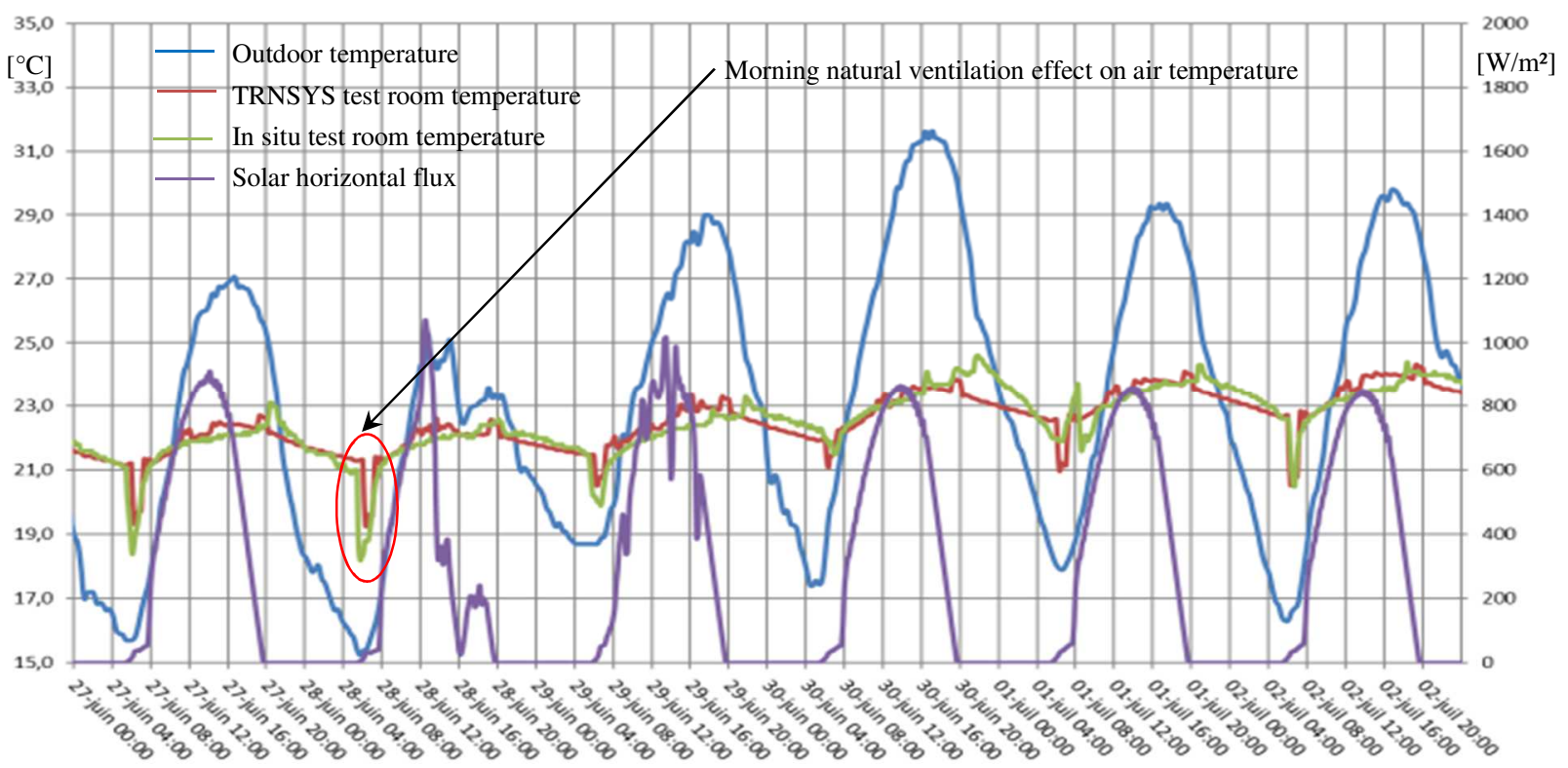

Figure 15: Air temperatures comparison between TRNSYS and in situ test during the hottest week.

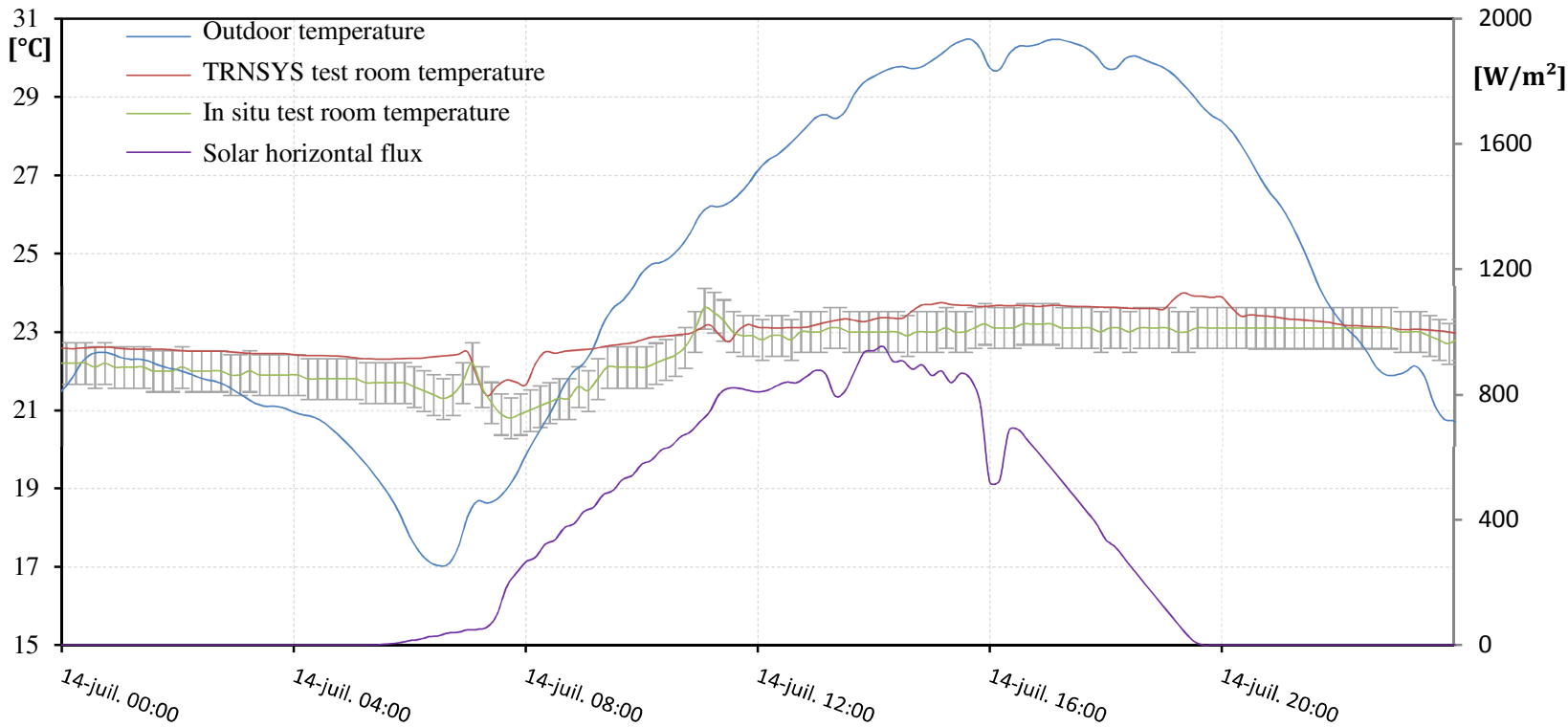

Figure 16: Air temperatures comparison between TRNSYS and in situ test during the hottest day.

In particular, we see the strong and punctual impact of the morning natural ventilation in this room. We also observe an efficient thermal behavior of the building in terms of summer thermal comfort with high damping and low indoor temperatures in comparison with outdoor temperatures. Figure 16 focuses on the hottest day of the test period. Uncertainty range has been plotted to proove the good correlation at least for this day. We also observed a satisfying correlation between TRNSYS wall temperatures outputs and in situ measurements, in particular for the inner face that leads to validate the identification procedure.

Finally, we consider the equivalent thermal properties determined previously as valid thanks to the very good correlations between in situ measurements and TRNSYS simulations using equivalent thermal properties to simulate a complex integrated insulation clay hollow block. Besides, it is interesting to note that our validation procedure relies on a discretized finite difference model while TRNSYS uses a conduction transfer function CTF to calculate 1D transient heat conduction through multilayer envelope components, which is different and complementary method (Delcroix, 2012). Finally, these in situ tests allow validating the relatively low equivalent heat capacities values found for hollow clay bricks. 


\section{Conclusion}

A complete numerical and experimental procedure has been carried out to assess equivalent thermal properties of complex wall construction blocks (integrated insulation clay hollow blocks). This procedure is based on laboratory tests, a 1D finite difference numerical model, TRNSYS simulations and in situ tests. The results show a successful calibration of the 1D model based on experimental data. Finally, the equivalent thermal properties of the material were found for a $36 \mathrm{~cm}$ thick block (CLIMAmur 36). It was interesting to show that these values (on the thermal capacity in $J / K / \mathrm{m}^{3}$ ) were below than the mean values of the properties of the 2 materials according to their proportion. This point shows the complexity to assess these equivalent values and shows that modelers have to pay attention to the used thermal properties of this kind of blocks for thermal comfort applications mainly.

In the future, more blocks references have to be tested to get their equivalent properties. Some others references (CLIMAmur 30, GF R20, R37) have already been tested but not until in situ tests which are obviously difficult and heavy to implement (see Table 5). Only 1D models and experimental tests on $1 \mathrm{~m}^{2}$ wall sample have been made. But these tests allows to confirm this trend to relatively low equivalent heat capacities. An experimental test on aerated concrete blocks has also been conducted to compare its properties with the clay hollow blocks:

Table 5: Equivalent thermal properties for several blocks.

\begin{tabular}{|c|c|c|c|c|c|}
\hline & $\begin{array}{c}\text { CLIMAmur } \\
\text { 36 }\end{array}$ & $\mathbf{R ~ 3 7}$ & $\begin{array}{c}\text { GF } \\
\text { R20 }\end{array}$ & $\begin{array}{c}\text { Aerated } \\
\text { concrete }\end{array}$ & \\
\hline$\rho_{e q}$ & 630 & 690 & 700 & 450 & $\mathrm{~kg} \cdot \mathrm{m}^{-3}$ \\
\hline$c_{p e q}$ & 430 & 435 & 475 & 800 & $\mathrm{~J} \cdot \mathrm{kg}^{-1} \cdot \mathrm{K}^{-1}$ \\
\hline$\lambda_{e q}$ & 0,08 & 0,12 & 0,2 & 0,11 & $\mathrm{~W} \cdot \mathrm{m}^{-1} \cdot \mathrm{K}^{-1}$ \\
\hline
\end{tabular}

Also, others studies would be relevant to conduct. Indeed, some authors well show the high sensitivity on thermal dynamic of these blocks (clay) to humidity transfers (dos Santos, 2009, Schmidt, 2012) which could modify the equivalent thermal properties. The guarded hot box would let to conduct a new campaign by adding these water transfers.

\section{Acknowledgement}

We thank the Wienerberger company for their technical, logistical and financial support and the Arconic company for their financial support.

\section{Nomenclature}

$\begin{array}{ll}c_{p}, & \text { heat capacity, } \mathrm{J} / \mathrm{kg} / \mathrm{K} \\ e, & \text { brick thickness, } m \\ h, & \text { superficial exchange coefficient, } \mathrm{W} / \mathrm{m}^{2} / \mathrm{K}\end{array}$

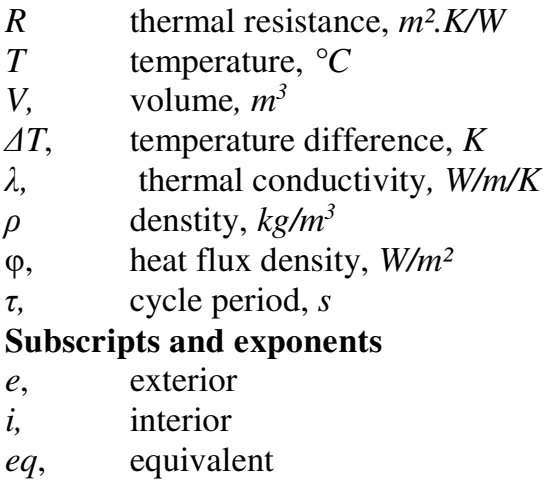

\section{References}

CSTB (2017), Réglementation thermique 2012, Règles Th-Bat, Fascicule matériaux

Emanuele Habib, Marta Cianfrini and Roberto de Lieto Vollaro (2017). Definition of Parameters Useful to Describe Dynamic Thermal Behavior of Hollow Bricks. Energy Procedia, Volume 126

Abdulrahman A. Alghamdi, Hamzah A. Alharthi (2017). Multiscale 3D finite-element modelling of the thermal conductivity of clay brick walls. Construction and Building Materials, Volume 157

Jan Kočí, Jiří Maděra, Miloš Jerman, Robert Černý, (2015). Computational assessment of thermal performance of contemporary ceramic blocks with complex internal geometry in building envelopes. Energy and Buildings, Volume 99

CTTB (edited by CTTB). (1997), Caractéristiques et performances thermiques du mur tout terre cuite, étude de la paroi seule, mesures expérimentales. (France), 6 pages

Arianna Brambilla, Thomas Jusselme, (2017). Preventing overheating in offices through thermal inertial properties of compressed earth bricks: A study on a real scale prototype. Energy and Buildings, Volume 156

B. Delcroix et al. (2012). Conduction transfer functions in TRNSYS multizone building model: current implementation, limitations and possible improvements. Proceedings from Fifth National Conference of IBPSAUSA. Madison, Wisconsin (USA), 2012.

Gerson Henrique dos Santos (2009). Nathan Mendes, Heat, air and moisture transfer through hollow porous blocks. International Journal of Heat and Mass Transfer, Volume 52

Simon Schmidt, Manuel Lindauer et Michaela Hoppe (2012). Comparing TRNSYS and WUFI@plus simulation models- illustrated on models validated on measurements. Proceedings of the 5th IBPC, Kyoto (Japan), 2012. 